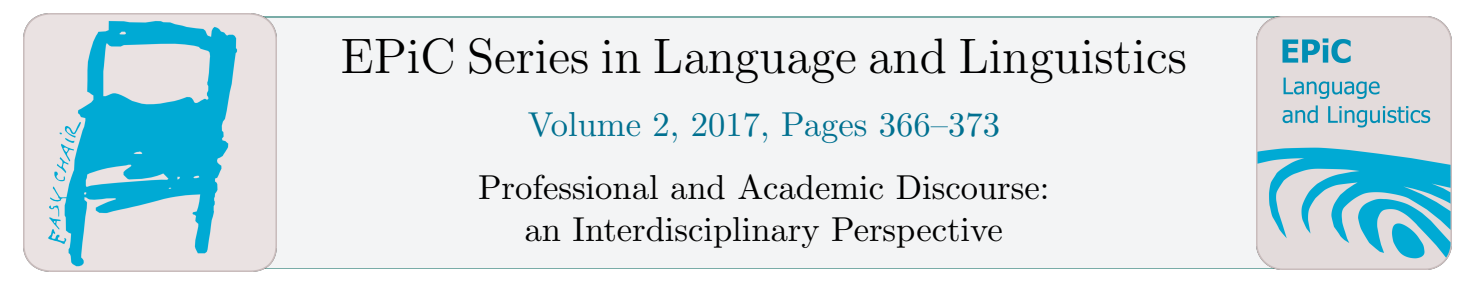

\title{
Translating False and Fickle Anglicisms in Modern Spanish
}

\author{
Andrew Samuel Walsh \\ Comillas Pontifical University Madrid, Spain \\ aswalsh@comillas.edu
}

\begin{abstract}
Modern Spanish is increasingly peppered with Anglicisms in all lexical fields, both professional and informal, and this tendency shows no signs of waning. On the contrary, all forms and registers of Spanish seem to be infused with numerous Anglicisms and not only such predictable spheres of influence such as business and technology. Many of these terms are loanwords which have occupied a genuine lexical gap in Spanish, are used appropriately and provide a genuinely useful service to speakers of the language. Nevertheless, there is also a great deal of misuse of these Anglicisms, both in terms of their meaning and their grammatical function and this inevitably leads to an undeniable source of potential confusion that needs to be addressed both by language teachers and translators in terms of the transmission and the transfer of these items of vocabulary between English and Spanish.
\end{abstract}

Keywords: False Anglicisms, translation, semantics

\section{Introduction}

In this article, we propose an analysis of four types of transformation and adaptation in the use of false Anglicisms that we have identified between modern Spanish and English:

- Grammatical transformation

- Lexical reduction

- Pseudo Anglicisms

- Faux or 'cod' Anglicisms

Before we analyse each category in more detail, we feel that a brief historical consideration of the phenomena of loanwords and Anglicisms in Spanish and an overview of the current situation will help us to provide the theoretical basis with which to properly understand the profound and compelling tendency towards the use of false Anglicisms in contemporary Spanish and its consequences for second language use and Spanish-English translation. 


\section{Historical and Social Background of Anglicisms in Spain}

The thorny translational issue of false Anglicisms is inextricably bound to the eternal problem posed for language acquisition and translation by the more widely studied question of false friends, a problem identified as long ago as 1928 in the seminal study made by Maxime Koessler and Jules Derocquigny. The conventional dynamic of loanwords is that the donor language term enters the recipient language as a technical term due to exposure to foreign culture (e.g. business and computer terminology) in a field in which the foreign culture has a dominant and prestigious role. Although this is certainly true of the ubiquitous presence of Anglicisms in modern Spanish, this has by no means always been the case. Indeed, for historical and political reasons, the traditional influence on Spanish bureaucratic and political language was exerted by French and this hegemonic tendency was maintained until well into the twentieth century. The onset of the cultural, economic and political dominance of the USA after the Second World War would eventually come to change all of this, although French was the language taught at Spanish schools until the 1980s and knowledge and use of the English language had only made some modest inroads in Spain due to the widespread boom in tourism from the 1960s onwards. The phenomena of globalization and the spread of the Internet around the turn of the century would finally consolidate English as the foreign language of choice in Spain in fields such as business, advertising and education.

Nowadays, it is reasonable to state that over the last few decades the Spanish have been and remain enthusiastic adopters of Anglicisms in myriad fields where English is deemed to be prestigious such as business ('startups', 'spinoffs'), computing ('hackers', 'routers'), ${ }^{1}$ bakery ('muffins', 'cupcakes'), fashion ('peeptoe', 'it girl'), beauty treatments ('lifting', 'peeling') and the cinema ('spoilers', 'trailers') Nowadays, this linguistic tendency is rampant even when there is a perfectly adequate Spanish term and therefore no lexical gap. ${ }^{2}$ Peninsular Spanish has traditionally shown a preference for loanwords rather than calques as evinced in the historic case of the dual Spanish terms for 'football': the form that came to dominate is the phonetically Hispanicized loan form 'fútbol' and the alternative calque 'balompié' is positively archaic and is hardly ever used. ${ }^{3}$

Nevertheless, there are official organizations such as the RAE (the Spanish Royal Academy of the Language) and the Fundeu BBVA ('Fundacion del Español Urgente' or the 'Foundation for Urgent Spanish') whose mission is to defend the correction and even the purity of the Spanish language in the face of the tremendous pressure exerted by the English language. ${ }^{4}$ In a clear example of this linguistic pressure, the battle between the English term 'smartphone' and the Spanish calque 'teléfono inteligente' ended with a resounding victory for the former over the latter, as has occurred with the much simpler binomy of 'tablet' in English and 'tableta' in Spanish. However, with the exception of the occasional admonition by the RAE regarding the excessive use of Anglicisms in Spanish advertising, ${ }^{5}$ in contemporary Spain there has been no equivalent of the resistance and downright hostility towards Anglicism in the autochthonous language found in certain official circles in France, a movement that reached its culmination in the 'Toubon Law' which was passed to protect the use of the French language

\footnotetext{
${ }^{1}$ Few modern Spaniards would be able to name the officially sanctioned Spanish translation of the term 'router' ('encaminador').

${ }^{2}$ Spanish Public Television (RTVE) has recently used the term 'birdwatching' which is generally incomprehensible to most contemporary speakers of Spanish, rather phonetically unsuitable to assimilation into Spanish, and refers to a relatively uncommon practice in modern Spain.

${ }^{3}$ The only notable exception is to be found in the full name of the Seville football club Betis, who are officially known as 'Real Betis Balompié'.

${ }^{4}$ See for example the following story from the Fundeu's own webpage: El director de la RAE dice que los anglicismos son un peligro para el castellano [The director of the Spanish Royal Language Academy says that Anglicisms are a danger for Spanish]. Fundación del Español Urgente. Accessed from http://www.fundeu.es/noticia/el-director-de-la-rae-dice-que-losanglicismos-son-un-peligro-para-el-castellano-6580/ (11/06/2016)

${ }^{5}$ In May 2016, the RAE launched a media campaign to alert Spaniards to the absurd nature of much of the English used in adverts, including mock adverts for a perfume called "Swine" and a range of sunglasses with "blind effect".
} 
from encroaching Anglicization as far back as 1994. France is by no means the only exception to the relatively relaxed Spanish approach to Anglicisms and, in this sense, it is worth noting how certain political groups in Russia have lately adopted their own rearguard against what they perceive to be the constant encroachment of the English language. ${ }^{6}$

The nature of modern Anglicisms in Spanish is fundamentally characterized by two origins: lexical gaps and sociolinguistic fashion. Currently, some 25,000 neologisms are coined in English every year of which around 8,000 make it into the dictionary. This case of linguistic dynamics is ineluctable as English is currently generating such a vast quantity of new lexemes in so many semantic fields and so many inventions and so much innovation stem from English speaking culture that English has undoubtedly become the new Latin lingua franca of science and technology. This process is currently occurring at such a relentless pace that there is almost no time to find a satisfactory translation in Spanish when the media decide to adopt and extend new Anglicisms so quickly. In this sense, it should be remembered that the RAE is a rather slow and traditional institution in the times of the Internet and official is only updated after an elapse of ten years.

In these circumstances, the Spanish language tends to choose the easy option of loanwords or, in the worst case scenario Spanglish (such as 'footing' or 'zapping', which are believed to have originally come from French). Another parallel phenomenon which affects translation and the general use of modern Spanish is what are known as Anglicisms of repetition, the mistaken use of a cognate in Spanish to reproduce the original term. A clear example would be the use of 'desorden' to translate the medical term 'disorder', instead of using the correct equivalent which is 'trastorno'. ${ }^{7}$ Indeed, Anglicisms of repetition are also invading scientific writing in Spanish, where people regularly speak of 'topicos' rather than 'temas', thus relegating a topic to the category of a cliché.

The widespread practice of TV dubbing is another major culprit. Translators are generally poorly paid and overworked on tight deadlines, a situation which is not conducive to good translation and which, due to the mass influence of television, tends to lead to greater contamination of modern Spanish by Anglicisms (and the influence of poor translation in dubbing on modern Spanish would be worthy of a further, detailed study). The temptation to quickly introduce an Anglicism into the Spanish language is enormous as evinced by the swift and complete adoption of the term 'selfie', and in other less wellknown cases the perceived social and professional prestige of using English terms has frequently led to some rather absurd adoptions such as 'flagship store' which is now widely used but very infrequently understood.

Several authors have previously approached this question both from a taxonomical perspective, in the case of the eight categories of Anglicism proposed by Furiassi (2010) and the five established by Balteiro and Campos (2012), and from a thematic perspective, in the case of sport by Campos Pardillos (2015) and Walsh (2015), economics by López Zurita (2005) and medicine by Candel Mora and Ricart Vaya (2009). Nonetheless, we feel that there is scope for a more specifically didactic and practical approach to this translational issue and, therefore, we propose a more reduced and readily accessible categorization for use by English language and English-Spanish translation students. Thus, having taken an overview of the main aspects of this question and its historical background, we will now analyse each category in further detail and with reference to specific examples.

\section{Grammatical Transformation}

This tendency consists of a change in the grammatical function of the Anglicisms in question which in turn tends to permeate and contaminate subsequent English use by Spanish speakers. A clear example

\footnotetext{
${ }^{6}$ http://www.theguardian.com/world/2014/jun/19/russian-fine-foreign-words. Accessed 11/06/2016.

${ }^{7}$ This and other examples such as 'medicación' instead of 'medicamento' indicate a sad decline given the historically strong literary tradition of many notable Spanish doctors such as Gregorio Marañón and Luis Martín Santos.
} 
of this is the adoption of the English noun 'fashion' which in Spanish is used as an adjective and therefore leads to solecisms such as 'this shirt is fashion'. As stated previously this is quite a common phenomenon in terms of the use of Anglicisms in modern Spanish and is prevalent in both informal and technical use of English. An extremely popular recent incorporation to modern Spanish is the term 'friki' which is largely used as a noun and is derived directly from the English word 'freak'. The word is not only altered grammatically, thus leading to mistranslations such as 'he is a freaky', but its adoption into Spanish has also included a certain semantic reduction as it is typically used in a wholly pejorative sense of strange or weird behaviour and thereby loses the possibility of referring to somebody with a consuming passion for a subject such as a 'jazz freak'. Another extremely prevalent example is the use of the term 'top' as a lone standing noun rather than adding it to a noun form as in English. In this way, ‘the German top model’ becomes ‘la top alemana'.

\begin{tabular}{|l|l|}
\hline \multicolumn{2}{|c|}{ Grammatical Transformations } \\
\hline \multicolumn{1}{|c|}{ Current Use } & \multicolumn{1}{c|}{ Correct Use } \\
\hline Un crac(k) & A top player or a crack player \\
\hline Un friki & A freak \\
\hline Fashion e.g 'Estás muy fashion’ & Fashionable or trendy \\
\hline Una top & A top model \\
\hline
\end{tabular}

Table 1: Grammatical Transformations

\section{Lexical Reduction}

This phenomenon consists of the reduction of an English term to the use of the first word only, thus leading to mistakes and confusion when the word is backtranslated into English. A very common example is the use of the word 'catering' as a noun to refer to any kind of 'catering company' or 'catering service'. This tendency to lexical reduction leads to rather clumsy and incorrect expressions in English such as 'my sister has a catering'. ${ }^{8}$ Business is a particularly fertile field for the adoption of Anglicisms as English is undoubtedly regarded as the lingua franca of the global economy and the Spanish business world is acutely aware of the need to understand and use the relevant terminology, a terminology which has historically has often been left in the original English language form. Perhaps the most significant example is the term 'marketing' which in Spain has completely displaced the Spanish alternative of 'mercadotecnia' which has long been vainly recommended by the RAE in its official dictionary. Although there is a clear case to be made for the existence of lexical gaps in a field such as business terminology which is logically in constant evolution, there is also undoubtedly a strong element of snob value and associated prestige to be derived from the adoption and use of the latest English business jargon which can serve as a kind of shibboleth to separate the supposedly Anglophone elite from the uninitiated. As stated previously, a very common procedure in this type of lexical reduction is to merely use the first element of a compound noun such as 'top' (model), 'basket'(ball) or the currently ubiquitous 'pen' to refer to a memory stick or flash memory and which is derived from the original compound 'pen drive'.

\footnotetext{
${ }^{8}$ The confusion is compounded by the tendency to mispronounce the word so that it sounds similar to the name 'Katherine' so that the assertion 'I am waiting for the catering' can be thoroughly misunderstood.
} 


\begin{tabular}{|l|l|}
\hline \multicolumn{2}{|c|}{ Lexical Reductions } \\
\hline & \multicolumn{1}{c|}{ Correct Use } \\
\hline Un burger & A hamburger bar/restaurant \\
\hline Un after work & A drink after work \\
\hline Un pen (drive) & A memory stick/ A flash USB memory \\
\hline Basket or 'básquet' (according to the RAE) & Basketball \\
\hline Renting & Car rental or car hire \\
\hline Un reality & A TV reality show \\
\hline
\end{tabular}

Table 2: Lexical Reductions

\section{Pseudo Anglicisms}

This phenomenon refers to the unconscious use of a false Anglicism in the mistaken belief that this is the correct English term. The use of the word 'ticket' is perhaps the most flagrant case of the adoption and widespread misuse of a false Anglicism as it tends to refer to all kinds of receipts and is actually not used for the document used to travel or the piece of paper that allows us to gain entry to a concert or sporting event. In line with the classic origin of loanwords, as English is often considered to provide a certain prestige by association in fields such as medicine, this leads to the use of pseudo Anglicisms such as a 'lifting' to refer to the practice of a 'face lift' in the field of cosmetic surgery. Sport, and particularly football, provides a rich seam of false Anglicisms due to the Anglo-American origins of most of the games which are most popular in modern Spain. Historically, this has led to the adoption of English terms used in a way that would not be readily understood by a native English speaker no matter how familiar he or she might be with the sport in question. A classic example of this is the use of the English word 'mister' to refer to the 'manager' ${ }^{\text {' }}$ of a football team. Another curious extension of this use of pseudo-Anglicisms is to be found in the case of the term 'un crac', which was and still is used to refer to an outstanding football player (i.e. a 'crack player') and has now been informally extended to describe anybody who has shown excellence in any given field. Thus, a prestigious chef could be called 'un crac' or, more informally, the term is used among friends to congratulate somebody in relation to any kind of personal or professional achievement ('eres un crac!') Indeed, the whole vocabulary of Anglo-origin sports such as football means that Spanish football vocabulary is peppered with more or less faithful and accurate Anglicisms, although some of these inevitably lead to a rather tortuous Spanish pronunciation of items such as 'goal average' and 'hat trick' rather than opting for calques. Given the abundance of English speakers buying into the Spanish housing market, several cases of curious loanwords and pseudo Anglicism have also occurred in this field to occupy the lexical gaps created by the differing nature of homes in both cultures. The influx of British people into the countryside of southern Spain, often fuelled by the 'good life' bucolic fantasies of travel literature has led to the adoption by English tongues of such a quintessentially Andalusian concept as a 'cortijo' for a small country house or cottage, a word whose difficulty is compounded by its challenging pronunciation for non-Spanish speakers. In terms of pseudo Anglicisms, perhaps the most striking example is the ready adoption of the word 'urbanization' as a direct loan of the Spanish term 'urbanización' to refer to a communal housing development. In our view, the adoption of this pseudo-Anglicism by British ex-pats and Spanish estate agents is entirely comprehensible given the fact that it manages to avoid the rather pejorative connotations of the English term 'housing estate' at the cost of being rather confusing when used out of this very specific cultural and commercial context.

\footnotetext{
${ }^{9}$ Curiously, the Anglicism 'manager' is in fact widely used in Spain to refer to the agent of an artist or entertainer.
} 


\begin{tabular}{|l|l|}
\hline \multicolumn{2}{|c|}{ Pseudo Anglicisms } \\
\hline \multicolumn{1}{|c|}{ Current Use } & \multicolumn{1}{|c|}{ Correct Use } \\
\hline $\begin{array}{l}\text { Tuning (this also gives us the hybrid forms } \\
\text { 'tunear') }\end{array}$ & Customizing \\
\hline Cantar en play back & To lip-synch \\
\hline Un casting & An audition \\
\hline Un córner & A store in a store \\
\hline Smoking/esmoquin & Tuxedo or dinner jacket \\
\hline
\end{tabular}

Table 3: Pseudo Anglicisms

\section{Faux or Cod Anglicisms}

This increasingly popular tendency refers to the practice of knowingly using a false Anglicism, usually based either on the humorous conflation of a Spanish lexeme with an English word ending or on the deliberately direct translation of a quintessentially Spanish term or expression. An example of the former tendency is to be found in the deliberately comic use of terms such as 'tumbing' (from the Spanish verb 'tumbarse' which means 'to lie down') or 'puenting' (the rendering of 'bungee jumping' which adds the Spanish word for bridge ('puente') to the universally popular English gerundial form. The 'positive' humorous use of false friends can also be echoed in knowing misuse of cod Anglicisms in the form of the playful use of deliberate direct mistranslation in the publishing phenomenon known as 'From lost to the river' ${ }^{10}$ As we have seen previously, this is an increasingly popular trend in modern Spanish and one which is to be found widely in informal conversation and the media. Any attentive student of trends in modern Spanish will immediately detect the perhaps excessive fondness for the 'ing' ending which seems to hold an irresistible allure for modern Spanish speakers who liberally insert English terms such as 'shopping' or 'drinking' into their conversations. However, this relish for the English gerund form is by no means limited to genuine Anglicisms used in a relatively coherent context, but is also freely extended to what we would called 'faux or cod Anglicisms' in the form of knowingly incorrect but entirely comprehensible Spanglish constructions or nonce words such as 'puenting' or 'tumbing'. This trend seems to show no sign of waning as evinced the currents terms such 'mamading' (a term used to refer to oral sex in public spaces such as bars) and 'balconing' (the dangerous and frequently fatal practice of jumping from a hotel balcony into a swimming-pool several floors below) that have been coined to describe the misbehavior of predominantly English-speaking tourist in Spain's coastal resorts. ${ }^{11}$ Through their exposure in the ensuing media scandal, they have quickly entered the collective consciousness and it seems that any form of new social behaviour is best expressed through a neologism that blends a Spanish term with the recurrent -ing word ending. Several well-known Spanish companies such as the airline Vueling or the online travel agency Nautalia are particularly fond of this option and have adopted it with enthusiasm in their advertising campaigns. ${ }^{12}$

\footnotetext{
${ }^{10}$ The expression 'from lost to the river' is the literal translation of the Spanish saying 'de perdidos al río' and its nearest equivalent in English would be 'in for a penny, in for a pound.' This was also the title given to a successful book of English 'versions' of traditional Spanish sayings and was followed up by another volume called 'Speaking in Silver'. The popularity of this phenomenon shows no sign of waning and is largely due to the widely held, self-deprecating perception among Spaniards that their command of English still leaves a lot to be desired.

11 See for example the following news story: http://www.huffingtonpost.es/2014/07/25/mamadingbaleares_n_5620132.html. Accessed 03/06/2016.

${ }^{12}$ Nautalia recommends its customers to try 'tomandoelsoling' (sunbathing in Spanish is 'tomar el sol') and 'mojiting (from 'mojito'), whereas Vueling has based its entire advertising on the ironic use of Spanglish.
} 


\begin{tabular}{|l|l|}
\hline \multicolumn{2}{|c|}{ Faux or 'Cod' Anglicisms } \\
\hline Balconing & \multicolumn{1}{c|}{ Correct Use } \\
\hline Puenting & $\begin{array}{l}\text { Jumping from a hotel balcony ('balcón' in } \\
\text { Spanish) into a swimming-pool, often resulting } \\
\text { in death or serious injury }\end{array}$ \\
\hline Tumbing & $\begin{array}{l}\text { Bungee jumping. From the Spanish word for } \\
\text { 'bridge' ('puente) }\end{array}$ \\
\hline Edredoning & $\begin{array}{l}\text { Lying down on a sofa. From the verb 'tumbarse' } \\
\text { (to lie down) }\end{array}$ \\
\hline
\end{tabular}

Table 4: Faux or 'Cod’ Anglicisms

\section{Conclusions}

Given the current hegemony of the English-speaking world in such diverse spheres as technology, culture, business and fashion, Anglicisms are clearly here to stay and the task facing those who care about the correct use of them in Spanish is to distinguish between the genuinely useful loanwords and the thoroughly dispensable alternatives to currently existing and perfectly acceptable Spanish terms. The tendency towards enthusiastic over-adoption is clearly expressed in the case of the well-established 'Anglicism' 'overbooking', which is now widely used to refer not only the widespread practice of selling too many tickets for a plane journey but also to any form of overcrowding whether it be in a lift, on public transport or in a bar. What many linguists regard as the 'contamination' of the Spanish language by Anglicisms tends to lead to phenomena such as overuse of the passive ('el sida puede ser curado' rather 'el sida se puede curar') and there are also plentiful examples of somewhat questionable phonetic adaptations such as 'randomizar or 'chequear' in the field of medicine, terms which purists tend to reject outhand as barbarisms and which, in the case of the first example but not the second, have not yet gained full access to the official RAE dictionary of the Spanish language. In this article, we have tried to provide an overview and a structured analysis of the question of false Anglicisms in modern Spanish by means of the establishment of four categories which characterize this linguistic phenomenon. Nevertheless, we are sure that there is ample scope for further detailed analysis of this tendency towards lexical misappropriation in fields such as business, fashion and sport. An additional problem which we have seen in the study is the growing assimilation of false and fickle Anglicisms through their transformative adoption into modern Spanish in a way that hardly corresponds to their use and meaning in English, or in some cases represents an entirely concept in the recipient language. Among the more linguistically concerning consequences of the phenomenon of false and fickle Anglicisms in modern Spanish is the contamination of the language caused by mistranslation when using English. In conclusion, this paper has sought to establish four main categories of false Anglicisms that each could be the subject of a further, more detailed study and should also be addressed in the English Language and Translation Studies classroom. 


\section{References}

Balteiro, I \& Campos, M.A, (2012). "False anglicisms in the Spanish language of fashion and beauty" in Ibérica 24, pgs 233-260

Campos, M.A. (2015). "All is not English that glitters: False Anglicisms in the Spanish Language of Sports" in Atlantis, 37.2, pgs155-174

Candel Mora, M.A. \& Ricart Vaya, A. (2009). "Emerging vocabulary: the influence of English on medical Spanish” in Revista Alicantina de estudios Ingleses, 22

Furiassi, C. (2010). False anglicisms in Italian. Monza. Polimétrica.

López Zurita, P (2005). "Economic anglicisms: adaptation to the Spanish linguistic system" in Ibérica 10, pgs 91-114.

Walsh, A. (2015). "T.M.I. (too much information)? - the pitfalls of translating Spanish football language into English." in AIETI7. New Horizons in Translation and Interpreting. Editions Tradulex. Geneva. 